\title{
Drug Addiction and Vitamin D Supplementation: How to Address a Health Concern in Methadone Treatment?
}

\author{
Hosein Effatpanah ${ }^{1,{ }^{*}}$ and Saeed Nateghi ${ }^{2}$ \\ ${ }^{1}$ Department of Public Health, Asadabad School of Medical Sciences, Asadabad, Iran \\ ${ }^{2}$ School of Medicine, Ziaeian Hospital, International Campus, Tehran University of Medical Sciences, Tehran, Iran \\ "Corresponding author: Department of Public Health, Asadabad School of Medical Sciences, Asadabad, Iran. Tel: +98-9123359312, Email: m.effatpanah@gmail.com \\ Received 2020 May 19; Revised 2020 June 14; Accepted 2020 June 18.
}

Keywords: Drug Abusers, Methadone, Opioid Substitution Treatment

\section{Dear Editor,}

A research paper written by Ghaderi and colleagues entitled "The effects of vitamin D supplementation on withdrawal symptoms and the expression of inflammatory cytokines and insulin in patients under methadone maintenance treatment: a randomized, double-blind, placebocontrolled trial" has been recently published in your peerreviewed journal (1). In our view, the study is novel and important due to two main reasons: first, authors have highlighted the substantial effects of vitamin D supplementation on reducing the side effects of high doses of methadone administration and promoting the quality of life (QoL) in methadone patients (1). Illicit drug use, particularly stimulants, opium, and heroin use, is still a nationwide concern in Iran, which is associated with critical health consequences (2-4). Most importantly, due to the negative effects of illicit drug use on the general health of methadone patients, such as poor mental and physical health, low QoL, and low treatment compliance, this issue is of crucial importance (1-4).

Ghaderi and colleagues conducted a study on 40 methadone patients in Kashan (Iran). Overall, 50,000 IU vitamin D vs. placebo were implementing every two weeks for 12 consecutive weeks (1). The study findings indicated how vitamin D supplementation made a significant change in reducing the side effects of methadone and how patients' QoL was positively changed (1). Second, the study is important because few studies have investigated the effects of prescribing vitamins in improving the health of methadone patients in Iran. Vitamins are likely to improve the physical and mental health, which may, in turn, promote methadone treatment outcomes. The role of minerals and vitamins in reducing psychiatric disorders has been well-established in the international research litera- ture (5). But, more similar research studies are needed on methadone patients in Iran.

In our view, Ghaderi et al.' trial study (1) aimed to identify and investigate a widespread health problem in Iran is influential. Obviously, a number of patients may leave methadone treatment due to the lack of sufficient vitamins, supplements, low QoL, and the potential negative impacts of methadone on their well-being. However, Ghaderi et al.'s study (1) has several key points which should be taken into consideration in designing future studies:

1) Ghaderi et al.'s research trial (1) is a small study that may not be generalizable to all methadone patients. Therefore, a larger randomized controlled trial study is needed. Also, special attention should be paid to gender differences. Women may need more vitamin D supplementations than men. This issue needs to be investigated in future studies.

2) The sample size is not representative of the target population. Therefore, a larger sample size is needed to evaluate the impacts of vitamin D supplementation;

3) More centers should be included to evaluate better the impacts of vitamin D supplementation at a larger multicenter level;

4) In their study, the method of sample size calculation, randomization, and group allocation need to go further and include a detailed statistical description for designing future studies; and

5) The literature review indicates that the field of psychological treatments in methadone treatment services is emerging in Iran (6-8). Other important issues, such as the role of psychotherapy in health promotion, have been investigated in the research literature (9-11). A combination of psychological treatments, prescribing vitamin $\mathrm{D}$, and 
even regular physical exercise needs to be considered in future studies to evaluate the relevant long-term impacts on positive methadone treatment outcomes.

Most importantly, as a new research study in Iran, the paper benefits the clinicians and senior drug researchers by providing a summary of the existing evidence, generating new hypotheses, and revealing the research gaps. We suggest that the effects of combined use of vitamins, particularly vitamin D, and regular physical exercise on the methadone treatment outcomes and health promotion be investigated in future studies.

\section{Footnotes}

Authors' Contribution: All authors have contributed to writing, editing, and revising this letter.

Conflict of Interests: There is no conflict of interest.

Ethical Approval: No ethical approval was received to write this letter.

Funding/Support: No funding is reported.

\section{References}

1. Ghaderi A, Banafshe H, Aghadavod E, Gholami M, Asemi Z, Mesdaghinia A. The effects of vitamin D supplementation on withdrawal symptoms and the expression of inflammatory cytokines and insulin in patients under methadone maintenance treatment: A randomized, double-blind, placebo-controlled trial. Iran JPsychiatry Behav Sci. 2020;14(1). doi: 10.5812/ijpbs.86969.
2. Dana S, Effatpanah M, Mahjoub A. The new epidemic problem of psychoactive drugs at drug treatment centers of iran: Implications for education, prevention and treatment. Iran J Psychiatry Behav Sci. 2018;12(2). doi: 10.5812/ijpbs.63555.

3. Tavakoli M, Effatpanah M, Moradi A, Mahjoub A. Methamphetamine dependence among Iranian female methadone patients: A crosssectional survey of three cities of Iran. Iran J Psychiatry Behav Sci. 2018;12(2). doi:10.5812/ijpbs.62866.

4. Sami S, Effatpanah M, Moradi A, Massah O. Matrix model as an intensive rehabilitation in three methadone services in Iran. Iran Rehabil J. 2017;15(3):293-8. doi:10.29252/nrip.irj.15.3.293.

5. Rafiey H, Ghaderi S, Morovat B, Noori R, Effatpanah M, Mahjoub A et al. Amphetamine type stimulants use in the adult population of Tehran: Implications for long term rehabilitation. Iran Rehabil J 2017;15(4):303-8. doi: 10.29252/nrip.irj.15.4.303.

6. Effatpanah M, Rezaei M, Effatpanah H, Effatpanah Z, Varkaneh HK, Mousavi SM, et al. Magnesium status and attention deficit hyperactivity disorder (ADHD): A meta-analysis. Psychiatry Res. 2019;274:228-34. doi:10.1016/j.psychres.2019.02.043. [PubMed:30807974].

7. Salimi S, Effatpanah M, Mahjoub A. Motivational interviewing can facilitate entry to matrix treatment for methamphetamine dependence. Iran J Psychiatry Behav Sci. 2018;12(2). doi: 10.5812/ijpbs.63560.

8. Shakiba K, Effatpanah M, Moradi A. Cognitive-behavioral therapy for methamphetamine dependence among methadone-maintained patients. Iran J Psychiatry Behav Sci. 2018;12(2). doi: 10.5812/ijpbs.63615.

9. Omidi N, Rafie Khorgami M, Effatpanah M, Khatami F, Mashhadizadeh $\mathrm{M}$, Jalali A, et al. Association between ABO blood group and severity of coronary artery disease in unstable angina. ARYA Atheroscler. 2017;13(4):172-5. [PubMed: 29147127]. [PubMed Central: PMC5677320].

10. Khoramizadeh M, Effatpanah M, Mostaghimi A, Rezaei M, Mahjoub A, Shishehgar S. Treatment of amphetamine abuse/use disorder: A systematic review of a recent health concern. Daru. 2019;27(2):743-53. doi: 10.1007/s40199-019-00282-3. [PubMed: 31228128]. [PubMed Central: PMC6895313].

11. Effatpanah M, Moradi A. Methamphetamine dependence and technology-based interventions in Iran. Iran J Psychiatry Behav Sci. 2018;12(2). doi: 10.5812/ijpbs.62935. 